\begin{tabular}{|c|c|c|c|}
\hline Declination. & & & $\mathrm{x}^{\circ} 54^{\prime} .72 \mathrm{~W}$ \\
\hline Dip ... $\quad \ldots$ & & $\ldots$ & 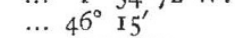 \\
\hline Total Force... & $\ldots$ & $\ldots$ & $\ldots$ I0.04850 \\
\hline
\end{tabular}

The value of the declination is very reliable, as it depends on observations taken every half hour from $6 \mathrm{~A}$. M. to $6 \mathrm{P}$.M. on four days each month in 1874, and on eight days a month in 1875 . The dip results from six complete observations, and the horizontal component of the intensity was determined twice a month in 1874 , and every week in 1875 .

Previous dip observations at Shang-Hai, by Sir E. Home in 1843 , and by Capt. Shadwell in $185^{\circ}$, give $-2^{\prime} \cdot 2$ and $-3^{\prime} \cdot 4$ as the secular variation for $185 \mathrm{I}$ and 1862 , the latter differing but slightly from the present variation in England.

Comparing the monthly means of the horizontal force for the winter and summer of 1874-75, we find an excess of 0.00074 in favour of the winter, when the sun is nearest the earth. The extreme variation is only 0.00577 , and both maximum and minimum occur in the summer months.

From a limited number of night observations it appears that the range of the declination needle is much more confined, whilst the sun is below the horizon than during the day hours. The diurnal variation is regular throughout the year, but the daily changes in winter are less simple than those of summer. The following are the mean results for the serarate seasons :-

$$
\text { Mean. Min. at Max. at }
$$

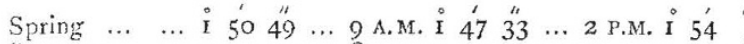

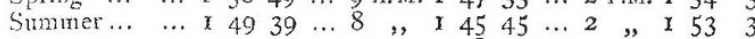

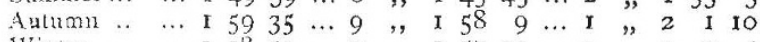

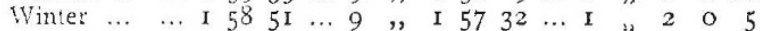

The time of the principal minimum is more constant than that of the maximum, the latter being anticipated by one hour in wioter

A sudden change from $x^{\circ} 50^{\prime} 13^{\prime \prime}$ on Sept. 21 to $1^{\circ} 56^{\prime} 5 I^{\prime \prime}$ on Sept. 26, 1874 , seems to require further confirmation (which it did not receive in 1875 ) before it can be considered as more than accidentally connected with the passage of the sun through the autumnal equinox.

The monthly mean value of the declination is greatest in November and least in June, and the absolute maximum and minimum were :-

and

$$
2^{\circ} 3^{\prime} 49^{\prime \prime} \text { at I ih. I } 5 \text { m. A.M. on November } 8 \text {, }
$$

$\mathrm{I}^{\circ} 4 \mathrm{I}^{\prime} 58^{\prime \prime}$ at 9 A.M. on June 29.

giving a yearly range of only $2 \mathrm{I}^{\prime} 5 \mathrm{I}^{\prime \prime}$, whilst the secular variation iamolmis to $+5^{\prime} \cdot 85$. The value on Nov. 8 was also evidently irceased by some irregular disturbance.

The comparison of the yearly means for the different hours with the hourly means for each season, shows that the sun's position with regatd to the equator has a decided effect on the magnetic declination, as increase and diminution in summer invariably correspond with diminution and increase in winter.

In discussing the hourly velocity of the needle, it is found that the acceleration is greatest between IO and II A.M., when the mignet is near its mean position, and that the A.M. max'mum velocity is an hour earlier, and the P.M. maximum an hour later in summer than in winter, the greatest velocity being about. $1^{\prime \prime} \cdot 5$ par minute.

The mean amplitude of the daily excursions of the declination magnet is $7^{\prime} \cdot 88$ in summer against $3^{\prime} \cdot 68$ in winter, June giving the raximum mean amplitude of $9^{\prime} \cdot 06$, and December the minimum of $2^{\prime} \cdot 95$. The value of $\mathbf{r}^{\prime} \cdot 92$ in February appears to be exceptional. The greatest extent of a daily oscillation in the cnurse of the twelve months was $I I^{\prime} \circ 5$ on June $I$, and the least $1^{\prime} \cdot \mathrm{r} 3$ on Feb. 20 , giving a maximum yearly variation of $9^{\prime} \cdot 92$.

The changes of the magnetic elements appear to be remarkably small throughout, and very free from irregular disturbances. The cure with which the observations are taken, and the efficient way in which they are discussed, are an earnest of the plentiful harvest we have every reason to expect from this land once so famous, but hitherto so neglected by modern science.

Stonyhurst Observatory, April I3

S. J. Perry

\section{THE CHALLENGER EXPEDITION}

$\mathrm{WE}$ have great pleasure in availing ourselves of the permission to publish the following correspondence which has passed through our hands, and in congratulating the staff of the Challenger, on having deserved so weighty a testimonial of success. It is an additional assurance that their three years' labour has not been in vain, that so many distinguished men of science have been impelled to speak of it in such terms, as well as a guarantee to the British Government that they did a wise thing in equipping the expedition; we hope it will be an encouragement to the latter to continue to deserve such golden opinions. To the Editor of "Nature"

Vienna, June 12,1876

SIR, - After having followed the reports of the naturalists of H.M.S. Challenger with the utmost interest, we beg leave to ask you kindly to transmit this simple but sincere expression of a hearty welcome and of thankful admiration to these distinguished gentlemen, as well as to the officers and the crew of this gallant ship, which has been called to render such prominent services to science. Yours most respectfully,

EDw. Suess, M. P. Prof. University, Vienna,

C. Claus,

G. TSCHERMAK,

F. STEINDACHNER, Director of the Imper. Zoolog. Museum,

Dr. Fr. Brauer, Custos of the Imper. Zoolog. Museum,

E. v. MARENZELLER,

Prof. Dr. J. HanN,

F. KARRER,

TH. Fuchs, Custos am k.k. Hof. Min. Cab.,

Palzeln, Custos am k.k. Zoolog. Cabinete.

To this the following reply has been made by Sir C. Thomson :-

To the Editor of "Nature"

20, Palmerston Place, Edinburgh, June 23, 1876

MY dear Sir, - I received your note and enclosure last evening. Will you allow me through you to express on my own part and on that of my colleagues Civilian and Naval on board the Chal. lenger, our deep gratification at the kind way in which the leaders of Natural Science in Vienna have expressed their approval of our efforts to extend the limits of knowledge in Phy sical Geography?

We hope that the Empire, which by the most instructive voyage of the Novara immediately preceded us in a similar line of research, may be among the first to aid in filling up the rich details of the new zoological region of which we have been able hitherto to supply only an outline.

I am, my dear Sir, yours very faithfully, C. WYVILLE THOMSON,

Director of the Civilian Scientific Staff of the Challenger Expedition.

ABSTRACT REPORT TO "NATURE" ON EXPERIMENTATION ON ANIMALS FOR THE ADVANCE OF PRACTICAL MEDICINE'

III.

\section{Experimental Researches on Ancesthesia Local and} General.

$T$ HE revival of methods for rendering surgical operations on men and animals perfectly painless, while it has been one of the greatest of the advances of modern medical art, has not been without its alloy. The present generation can scarcely appreciate what were the scenes of the operating theatre before the introduction of anæsthesia. The present generation that is not medical cannot appreciate now what is the scene at an operation when the agent employed to prevent pain proves an agent of death. One surgeon I know has been present at six of these fatal catastrophes under and from anæsthetics. Such an experience shakes the strongest heart. Here is a human being talking cheerfully and resigning himself with full confidence to his medical friends. The operation to be performed may be the act of seconds ${ }^{1}$ Continued trom p. ${ }^{5} 2$. 
only, but the dread of the pain enforces on the operator the necessity of administering the anæsthetic. A few inhalations of the narcotic vapour are made, and in an instant the body, a moment or two ago animated and fuil of life and energy, is lifeless in the hands of the aciministrator of the narcotic.

There is no more painful agony to a practitioner of medicine than a catastrophe of this character. He feels as if the whole beneficent art of anesthesia were, after all, a mockery; as if it were better that tens of thousands should suffer pain than that one should die under his directing hand merely to save a brief period of pain.

From the first of the reintroduction of anæsthetics these unhappy fatal failures from them have occurred to darken with the shadow of death the retreat of pain from the earth. What more natural, what more humane a labour than that which is devoted to the discovery of a means by which this shadow of death may also be made to fade from the picture? To me this labour has been a life's work. I have pursued it in two directions.

(a) By endeavouring to discover anæsthetic methods which shall carry with them no danger to life.

(b) By endeavouring to discover means that shall restore safety when danger is incurred from the use of the present imperfect anasthetics.

In conducting both these lines of research it has been nccessary to experiment on the inferior animals. There is no other method. If the most promising new chemical agent for anaesthesia were put into my hands to-day by the scientific chemist, I could not administer the agent direct to the human subject on mere speculation. It is true I have, from lone experience, been able so to understand the characters of anæsthetics that I can formulate then theoretically. If the chemist gives to me a sub. stance and tells me its atomic composition, its physical properties of solubility, of weight, vapour density, and boiling point, I know at once whether it is or is not an anæstheric, and I can reject on the spot some substances from and by reason of this knowledge, all of which, by the way, has been acquired by experimental research. But if the chemist gives to me the very thing I want it is still impossible to proceed to apply it to practice on man hefore testing its action on animals inferior to man, for I have found that some of the very simplest and seemingly most innocuous of substances are most fatal.

One of the pioneers of anæsthesia with whom I had the privilege to live and work, did once introduce into practice a new, effective, and, in atomic construction, very simple anasthetic. In the course of a comparatively few administrations of this agent to man, two deatis resulted. To the end of the useful life of this, my friend, he never ceased to regret that he had not first subjected the agent to more vigorous tests of action on animals inferior to man. Once in my researches I got under observation another anasthetic which seemed perfect. I should have introduced it into practice, had not the lesson I had learned above corrected the error. For on submitting the new agent to the required strain of experiment, I found it so fatal to animals that had I put it forward I should certainly have deepened the shadow of death on the picture of retreat of pain. Twice in the same manner I have prevented other men from introducing anæsthetics which did not bear the full test of proof of experiment on the inferior animal. The reasonable mind will take in all these practical points, and, I think, will come to the conclusion that for no application to the necessities of man and of all other animals could the lives of inferior animals be more justly applied. To kill animals for food, to apply them to works of useful labour, is not more just.

\section{Method of Experimentation.}

The method of experimentation I have pursued has taken two courses :-

(a) The subjection of animals to narcotising gases or vapours for the purpose of inducing in them anæstheric sleep, observing the action of the narcotic tbrough all its degrees of action, and the mode in which it destroys life when it is pushed to the point of destruction of life.

(b) The subjection of animals to local methods of abolishing pain, or, more correctly, of destroying pain in parts of the body locally, so that operations may be performe painlessly while the general consciousness re. mains, and without any danger at all to life.

In carrying out the first of these inquiries, the plan pursued was as follows :-A narcotising chamber was used, the precise capacity of which was determined. The chamber, made of glass and iron, was, when closed, air-tight, but it was furnished with openings through which it could be charged with the precise measures of the narcotic vapour or gas required. It was also so arranged that the temperature and dryness, and when necessary, pressure of the atmosphere within it could be moderated. Briefly, the chamber was so constructed that the action of every volatile narcotic substance could be tested in it under all known external conditions.

The animals subjected to experiment have as a rule been of two kinds - rabbits and pigeons. Rabbits have been used because when they are allowed to sleep to death in the vapour, or when they accidentally sleep to death, they are good subjects for examination after death, and tell clearly the reason of deatb. Pigeons have been used for two reasons : first because they succumb more easily to anresthetics than any other animals, easier even than man; secondly because during sleep they give indications of dangerous or troublesome effects, such as rigidity and vomiting, quite as easily as man. If, therefore, a pigeon will go safely and easily through an anæsthetic sleep, the inference is fair that a man will do so; and in all cases where I have found the anæsthesia so safe and satisfactory on these animals-rabbits and pigeons-as to commend the anæsthetic which produced it, I have always proceeded to try the effect on the human subject by inhaling the anæsthetic myself until it produced the insensible sleep.

In experimenting on the animals, they have been gently introduced into the narcotic chamber from above, and as they have passed into insensibility, each of the stages of narcotism-usually four in number-have been carefully recorded by their phenomena. The facts have been tabulated in set form so as to show, per-centage of vapour diffused, time required to produce insensibilicy, period of each stage, muscular disturbance, state of the respiration, state of the heart pulse, change of animal temperature, and condition of the pupil. In cases of recovery from the anæsthetic, the signs and period of recovery have been recorded; in cases of death in the anæsthetic sleep, the time and mode of cleath whether by the heart or by the respiration, have been recorded.

I should remark that these researches have not been made at any regular times. They have been suggested by the study of some chemical sulstance which presented some promising qualities for the object in view. I believe no new substance of this kind has for the last twenty-five years escaped my observation.

On the animals themselves no pain can be said to have been inflicted. The worst that has happened to them has been that they have passed into deep sleep and have waked again just as a human being who has taken chloroform successfully for an operation, sleeps and wakes. Or else they have passed into sleep and from sleep into death, a mode of dissolution so serene, so painless, as to be an enviable imitation of natural euthanasia.

In the researches on local means of relieving pain, the part to be anæsthetised has been simply subjected to the action of the anæsthetic. At first I used lower animals for this method of inquiry, but owing to their comparative low sensibility they proved unsatisfactory. A mode of local anæsthesia which on a dog or rabbit seems abso- 
lutely perfect may, I found, be most imperfect on a man or woman. I once thought I had established a perfect local anæsthesia by applying to animals narcotic solutions locally, in combination with a gentle continuous electric current. It scemed to me that the current caused a rapid absorption of the narcotic, or so acted with it on the minute blood-vessels as to produce contraction of them and destroy local insensibility. Under this plan I performed a number of operations on the lower animals without exciting the slightest evidence of pain. When I came to man the process broke down; some insensibility was, without doubt, produced, and seventeen operations were performed by the local plan. But the more exalted sensibility of the higher animal was not satisfied, and I learned that what would do perfectly for a dog was quite inefficient for a human being.

It is a curious episode in this research and worthy of record, that one of my scientific critics, the late Dr. Waller, a man of great genius, actually showed that he could perform on dogs without any anæsthesia at all, the same operations that I performed with this local anæsthesia, and with similar apparent freedom from pain. The result was that I continued all my after experiments on local anesthesia, first on my own body, and then on other human subjects who required such anæsthesia for operation. All my experiments with sprays to produce insensibility by intense cold, on Dr. James Arnott's most original design were first performed in this manner, and ti:e process was only applied to the inferior animals after it had been made perfect for the surgical purposes for which they required it. In this instance therefore man became the subject of physiological experiment for the benefit of the inferior animals as well as for his own.

\section{Primary Results of the Experimentation with Ancesthetics.}

The primary results of these experiments on different modes and processes for inducing anæsthesia may be put forward in a few sentences. They were all of them results which could not have been reached by any other line of research.

I. The experimentation has enabled me, as a physician, to keep on a level with the chemist in applying to the services of man all those agents for the relief of pain which the chemist produces. The chemical bodies of the methyl, ethyl, bulyl, and amyl series with several others which have promised to be of any service have been tested, and their respective values carefully chronicled.

2. For general anæsthesia I have been enabled, by the research to add many new and useful anæsthetics. Bichloride of methylene, which has been very largely used, and which Mr. Spencer Wells invariably uses with signal success for ovariotomy, came from this research. Methylic ether, the safest ancesthetic I have yet known, was proved by this research. Methylal, another very valuable agent of the same kind, and which has to be practically applied, is another good anæsthetic added by these inquiries; while several agents tried for ar æsthesia which have not answered, have been accidentally discovered to possess other and valuable curative properties. The introduction of the etherial solution of peroxide of hydrogen, an exceedingly useful remedy, and the local use of butylic alcohol for toothache, are two instances amongst many more of this kind.

3. The researches have enabled me to formulate the physiological properties of the organic bodies that produce anesthesia, so that the va'ue of the anæsthetic compounds may be calculated from their physical characters and composition. I have been able to show that some elementssuch as chlorine-are objectionable parts of an anæsthetic agent, others favourable; that certain degrees of solubility are objectionable, others favourable ; that certain vapourdensities are objectionable, others favourable. I have been able to point out a distinct theoretical standard of qualities which, being found, will yield a safe, manageable, and agreeable anæsthesia. Lastly, I may add, from an experience in the study of anæsthetics extended from the time when they were first introduced until this hour, the positive assurance that careful and steadily pursued experimental research must result in the discovery of all the laws relating to anæsthesia, and to the further discovery of an absolutely safe mode of producing it. For I have learned that no man, no animal, ever yet has died because it was rendered insensible to pain, and the deaths which have occurred have invariably been due to some property. of the substance used that had no relation to the anæsthetic property-some independent bad quality which we may fairly expect science to eliminate for the benefit of man.

4. While striving to apply the results of experimentation to the advantage of the human family, I have not forgotten the inferior creation, and in nothing have I been more successful than in their behalf. For operations on animals I have been able to make the application of local anæsthesia so perfect that there is no necessity whatever that any lower animal should ever feel a pang from the knife of the operator for any external cutting operation it may have to undergo. The Society for the Prevention of Cruelty to Animals has itself published the facts of an operation, for removal of a large tumour from a horse belonging to Sir Wm. Erle, that was performed by my method of operating under ether spray while the animal stood in the stable without halter or bridle, oblivious of all pain. That fact,--one of a hundred similar,-I put forward, not as in itself peculiar, but because of the record from which it is taken. It could not have been recorded even there but for the experimentation that gave it birth. BENTAMIN W. RICHARDSON

\section{NOTES}

Her Majesty bas been pleased to confer on Prof, Wyville Thomson the honour of knighthood.

IT is stated that Sir C. Wyville Thomson and the members of the scientific staff of the Challenger will be entertained at dinner in Edinburgh on July 7. The Lord Provost has consented to take the chair.

$W \mathrm{E}$ notice from the official announcement in connection with the Loan Collection, that during the present week, fourteen demonstrations of apparatus were given on Monday, eleven on Tuesday, four on Wednesday and Thursday, while seven will be given on Saturday. With regard to the com. plaint in the Times as to the occasioual non-attendance of the lecturers, it should be remembered that these demonstrations are given out of pure good-will by some of the most eminent and busy of the scieniific men of the day, who are not always masters of their own time. The Department's arrangements are entirely dependent on the convenience of these men, and it should not therefore be blamed if its proposed programmes are not always rigidly carried out. The following arrangements have been made for future free evening Lectures on the Instruments in the Collection :--Saturday, July I, Prof. Tyndall, F.R.S., on "Faraday's Apparatus," in the I.ecture Theatre, South Kensington Museum; Monday, July 3, the Right Hon. Lyon Playfair, C.B., M.P., F.R.S., on "A.ir and Airs," as illustrated by the Magdeburg Hemispheres and Black's and Cavendish's Balances; Saturday, July 8, Dr. Gladstone, F.R.S., "The Work of Davy and Faraday," as illustrated by the Apparatus lent by the Royal Institution; Monday, July ro, Rev. R. Main, M.A., F.R.S., on "The Instrumental Foundations of Practical Astronomy ; "Saturday, July I 5, Dr. W. H. Stone on "Modes of Eliciting and Reinforcing Sound;" Monday, July r7, Mr. C. V. Walker, F.R.S., on "Galvanic Time Signals ;" Saturday, July 22, Mr. W.Chandler Roberts, F. R.S. 